\title{
Reports
}

\section{Relationship between diastolic hypertension and myocardial morphology and function in elderly males with diabetes mellitus}

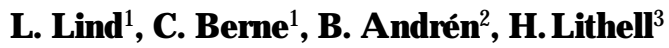 \\ ${ }^{1} \mathrm{D}$ epartment of Internal M edicine, U ppsala U niversity, U ppsala, Sweden \\ ${ }^{2}$ D epartment of C linical Physiology, U ppsala U niversity H ospital, U ppsala, Sweden \\ ${ }^{3}$ D epartment of G eriatrics, U ppsala U niversity, U ppsala, Sweden
}

Summary The existence of a distinct diabetic cardiomyopathy, characterized by a raised left ventricular mass, has previously been suggested. H owever, as diabetes mellitus is associated with both left ventricular hypertrophy and hypertension a confounding effect of raised blood pressure in diabetic patients has to be considered. In the present cross-sectional study an echocardiographical examination was performed as part of a health screening survey in 582 males, aged 70 years. A fter the exclusion of subjects with coronary heart disease or those on regular antihypertensive treatment, 30 normotensive subjects with diabetes were compared with 10 subjects with non-insulin-dependent diabetes (NIDDM) and a diastolic blood pressure $90 \mathrm{~mm} \mathrm{H}$ g or more and 203 normotensive control subjects with normal glucose tolerance. Both groups with NIDDM showed a significantly increased left atrial diameter $(4.4 \pm 0.7$ vs $4.0 \pm$ $0.5 \mathrm{~cm}, \mathrm{p}<0.05)$ and an increased atrial component in diastole (A -wave, $p<0.01$ ) compared to the control subjects. Left ventricular mass was, however, only marginally and not significantly elevated in the diabetic subjects when compared to the healthy control subjects ( $133 \pm 19$ and $133 \pm 28$ vs $128 \pm 25 \mathrm{~g} / \mathrm{m}^{2}$ ). $O$ nly in the subjects with concomitant diabetes and a raised blood pressure was the intraventricular septum significantly enlarged $(p<0.05)$. Thus, in the present sample no distinct diabetic cardiomyopathy with an increased left ventricular mass, independent of the influence of hypertension could be detected. The myocardial alterations in these diabetic males were restricted to an increased left atrial size and an impaired diastolic function. [D iabetologia (1996) 39: 1603-1606]

Keywords Non-insulin diabetes mellitus, hypertension, M-mode echocardiography, heart function.
It has been claimed that the diabetic state may influence myocardial morphology and function independently of induction of atherosclerosis [1-3]. R ecently the investigators in the Framingham H eart Study [4] suggested the existence of a distinct cardiomyopathy. H owever, in that study and in others, no distinction has been made between normo- and hypertensive diabetic patients. A s hypertension itself is known to induce major changes in myocardial morphology

Corresponding author: D r. C. B erne, D epartment of Internal M edicine, U niversity H ospital, S-751 85 U ppsala, Sweden A bbreviations: NIDD M, Non-insulin-dependent diabetes mellitus; O GTT, oral glucose tolerance test; D B P, diastolic blood pressure; IVRT, isovolumetric relaxation time; DT, deceleration time; LVOT, left ventricular outflow tract. and function, the effect of a raised blood pressure in combination with diabetes mellitus has to be taken in account.

In the present study the effects on myocardial morphology and function of diabetes alone, or combined with a raised blood pressure, were studied in a population sample of elderly males.

Subjects and methods

A cohort of 2322 men born in 1920-1923 were invited to a health survey in 1970-1973 [5]. A the 20-year follow-up of the U ppsala Health Survey, the first 582 consecutive subjects were given an electrocardiographic examination in addition to an oral glucose tolerance test (OGTT). 
Table 1. B asic characteristics, haemodynamic and morphological variables in healthy control subjects and in subjects with diabetes with or without a raised blood pressure

\begin{tabular}{|c|c|c|c|}
\hline & Control subjects & $\begin{array}{l}\text { D iabetes with } \\
\text { diastolic blood pressure } \\
<90 \mathrm{~mm} \mathrm{Hg}\end{array}$ & $\begin{array}{l}\text { D iabetes with } \\
\text { diastolic blood pressure } \\
\geq 90 \mathrm{~mm} \mathrm{Hg} \\
\end{array}$ \\
\hline $\begin{array}{l}\text { Number of subjects } \\
\text { Fasting blood glucose }(\mathrm{mmol} / \mathrm{l}) \\
\text { Fasting insulin }(\mathrm{pmol} / \mathrm{l}) \\
\text { Body mass index }\left(\mathrm{kg} / \mathrm{m}^{2}\right) \\
\text { Heart rate }(\text { beats/min) } \\
\text { Systolic blood pressure }(\mathrm{mm} \mathrm{Hg}) \\
\text { Diastolic blood pressure }(\mathrm{mm} \mathrm{H}) \\
\text { L eft atrial diameter }(\mathrm{cm}) \\
\text { Intraventricular septum thickness }(\mathrm{cm}) \\
\text { Posterior wall thickness }(\mathrm{cm}) \\
\text { E jection fraction }(\%) \\
\text { E /A ratio } \\
\text { I sovolumetric relaxation time }(\mathrm{ms}) \\
\text { M itral A -wave }(\mathrm{cm} / \mathrm{s}) \\
\text { L eft ventricular mass }\left(\mathrm{g} / \mathrm{m}^{2}\right) \\
\text { Total peripheral resistance }\left(\mathrm{dyn} \cdot \mathrm{s} / \mathrm{cm}^{5} \cdot \mathrm{m}^{2}\right)\end{array}$ & $\begin{aligned} 203 & \\
5.3 & \pm 0.55 \\
66 & \pm 35 \\
25.7 & \pm 3.1 \\
65 & \pm 12 \\
143 & \pm 16 \\
82 & \pm 7.8 \\
4.0 & \pm 0.52 \\
1.1 & \pm 0.13 \\
0.98 & \pm 0.11 \\
0.67 & \pm 0.08 \\
0.94 & \pm 0.25 \\
119 & \pm 22 \\
66 & \pm 15 \\
128 & \pm 25 \\
3058 & \pm 607\end{aligned}$ & $\begin{aligned} 30 & \\
7.7 & \pm 2.5^{\mathrm{a}} \\
102 & \pm 66 \\
27.6 & \pm 3.6^{\mathrm{c}} \\
63 & \pm 8.0 \\
149 & \pm 14^{\mathrm{d}} \\
80 & \pm 7.8 \\
4.4 & \pm 0.74^{\mathrm{c}} \\
1.1 & \pm 0.12 \\
0.99 & \pm 0.12 \\
0.64 & \pm 0.98 \\
0.87 & \pm 0.15 \\
122 & \pm 15 \\
75 & \pm 16^{\mathrm{c}} \\
133 & \pm 19 \\
3383 & \pm 861^{\mathrm{d}}\end{aligned}$ & $\begin{array}{l}10 \\
7.7 \pm 2.1^{\mathrm{a}} \\
114 \pm 66 \\
29.4 \pm 5.1^{\mathrm{a}} \\
78 \pm 10^{\mathrm{a}, \mathrm{b}} \\
159 \pm 14^{\mathrm{c}, \mathrm{b}} \\
93 \pm 2.5^{\mathrm{a}, \mathrm{b}} \\
4.4 \pm 0.68 \\
1.2 \pm 0.10^{\mathrm{d}} \\
1.02 \pm 0.10 \\
0.62 \pm 0.16 \\
0.83 \pm 0.31 \\
121 \pm 26 \\
81 \pm 18^{\mathrm{c}} \\
133 \pm 28 \\
3295 \pm 946\end{array}$ \\
\hline
\end{tabular}

Values are mean \pm SD. ${ }^{a} p<0.001$ vs control subjects; ${ }^{b} p<0.001$ vs diabetes with $D B P<90 \mathrm{~mm} \mathrm{H}$; ${ }^{c} p<0.01$ vs control subjects;

$\mathrm{d} p<0.05$ vs control subjects.

In the analysis of the 20-year follow-up data subjects with a history of hospital-treated myocardial infarction, a Q -wave on the ECG, or being treated with antihypertensive medication were excluded. Diabetes was defined on the basis of a $75-g$ OGTT, according to the criteria defined by the $\mathrm{N}$ ational $\mathrm{Dia}$ betes $\mathrm{D}$ ata $\mathrm{G}$ roup [6].

Blood pressure was measured in the supine position after 10 min rest by a mercury sphygmomanometer. $\mathrm{H}$ eart rate was evaluated by counting the pulse in the radial artery. No subjects with atrial fibrillation or other significant arrhythmias were included in the study.

A comprehensive two-dimensional echocardiography was performed with a Hewlett-Packard Sonos 1500 cardiac ultrasound unit (H ewlett Packard, A ndover, M ass., U SA ). A 2.5 $\mathrm{MHz}$ transducer was used for the majority of 2-D, M-mode and posterior wall-D oppler examinations.

Dimensions were measured with $M$-mode on-line and using a leading edge-to-edge convention. The measurements included left atrial diameter, intraventricular septal thickness, posterior wall thickness, left ventricular diameter in end diastole.

L eft ventricular mass was determined by using the $M$-mode formula of Troy according to the recommendations of the A merican Society of E chocardiography [7]. To correct for differences in body constitution, left ventricular mass was divided by body surface area.

L eft ventricular inflow though the mitral valve was measured by pulsed D oppler from the apical position. The peak velocity of the early rapid filling ( $E$-wave) and atrial filling ( $A$ wave) were recorded.

L eft ventricular outflow tract (LVOT) diameter was obtained from a parasternal long axis view, while the flow velocity integral was determined from the apical window, with the sample volume at approximately the same level as that from which the diameter measurement had been taken. From these two variables stroke volume (Doppler) was calculated as $\pi \times \mathrm{LVOT}^{2} / 4 \times$ flow velocity integral. Thus, stroke volume and consequently cardiac output were measured in two ways. Total peripheral resistance was calculated as $80 \times$ (mean arterial pressure-3)/cardiac output.

To correct for differences in body constitution, stroke volume, cardiac output, left ventricular mass and total peripheral resistance were divided by body surface area, thus giving stroke index, cardiac index, left ventricular mass index and total peripheral resistance index.

L eft ventricular volumes in systole and diastole were calculated according to the formula of Teichholtz and from that stroke volume, cardiac output and ejection fraction were calculated.

A Il examinations were performed with the subjects in the standard left lateral position and in expiratory apnoea or quiet breathing. The five best heart beats were chosen from which the average was calculated.

$B$ oth the performing and the reading of the images were done by one experienced physician (B . A .) unaware of the clinical data of the subjects.

A diastolic blood pressure of $90 \mathrm{mmH}$ g was used as the cutoff limit to separate normotensive subjects from those with an elevated blood pressure.

\section{Statistical analysis}

Factorial analysis of variance (A NOVA) with D unnett's posthoc test was used for statistical evaluation with $p<0.05$ regarded as significant.

\section{Results}

While the subjects with diabetes and a normal blood pressure showed a similar heart rate and diastolic blood pressure (D B P) as the heal thy control subjects, the addition of a raised blood pressure to diabetes not only resulted in a higher blood pressure, but also a significantly higher heart rate (Table 1).

The diabetic subjects with a DBP less than $90 \mathrm{mmH}$ g did, however, show a significantly elevated systolic blood pressure when compared to the control subjects, but no case with isolated systolic hypertension was found ( > $160 \mathrm{~mm} \mathrm{H} \mathrm{g}$ ). 
A s judged by the body mass index both diabetic groups were more obese than the control group, with no significant difference between the diabetic groups. A Iso, fasting blood glucose and fasting insulin levels were significantly elevated when compared to the control subjects, with no significant difference between the two diabetic groups.

On the other hand, both diabetic subjects with a normal DBP and those with a raised blood pressure showed a significantly increased diameter of the left atrium when compared to control subjects, whereas the difference did not reach statistical significance in those with a raised blood pressure. A similar trend was seen for both the mitral A -wave and total peripheral resistance. For both of these important haemodynamic variables, the presence of diabetes was significantly associated with higher values, while the addition of a raised blood pressure to the diabetic state did not add any further impairment (Table 1).

O nly a smaller non-significant trend towards an increased left ventricular mass was seen in both of the diabetic groups while the thickness of the intraventricular septum was increased in the diabetic patients with a raised blood pressure only (Table 1 ). Posterior wall thickness was similar in all three groups.

There were no significant differences in indices of systolic function or diastolic function mitral $E$-wave, the $E$ / $A$-ratio, isovolumetric relaxation time (IVRT) or deceleration time (DT).

\section{Discussion}

The present study showed that no disinct cardiomyopathy with an elevated left ventricular mass was seen in elderly males with NIDDM.

H owever, alterations in certain myocardial characteristics accompany diabetes and were not only due to the association between diabetes and hypertension.

Diastolic dysfunction has previously been described in diabetic subjects [8-1] and was confirmed in the present study. The diabetic patients were found to rely more on the atrial contraction to fill the left ventricle than normoglycaemic subjects. This would possibly be the consequence of a decreased left ventricular compliance, as the IV RT was normal; indicating normal relaxation properties of the diabetic left ventricle. A utopsy studies have shown an increase in interstitial fibrosis and collagen content in the hearts of diabetic subjects $[12,13]$, possibly disclosing the morphological basis for the decreased compliance of the diabetic heart.

The increased size of the left atrium in these diabetic subjects with a normal systolic function might reflect an increase in circulating blood volume. The sodium retention found in the diabetic state is likely to be the mechanism behind this finding [14]. Such an increase in preload might, through the Frank-Starling mechanism, compensate for any mild negative effect on systolic function that could accommpany diabetes, as suggested by Ferraro et al. [8]. A $n$ increased atrial size could also be a consequence of an impaired diastolic filling, but in these cases it is usually associated with a concomitant impairment of systolic function.

The total peripheral resistance was also elevated in both of the diabetic groups. A peripheral vasoconstriction has been shown to be a hallmark of established hypertension; the present study also demonstrated this in diabetes. It has been shown that insulin resistance and hyperinsulinaemia are accommpanied by a raised sympathetic nerve activity and elevated levels of circulating catecholamines $[15,16]$ that may be responsible for the increase in total peripheral resistance found in diabetic patients, regardless of blood pressure.

In contrast to the findings of the Framingham $\mathrm{H}$ eart Study [4], no major increase in left ventricular mass was seen among the diabetic subjects in the present study. A $n$ increase in the thickness of the intraventricular septum was only seen in the diabetic subjects with raised blood pressure. H owever, the Framingham $\mathrm{H}$ eart Study analysed diabetic subjects without excluding hypertension. In that study multiple regression analysis showed that diabetes was associated with an increased left ventricular mass only in women, when the influence of hypertension was taken into account.

The number of diabetic subjects was small and therefore any true significant difference between the groups could go unrecognized, but would be of minor importance as the non-significant difference between the diabetic and the healthy control subjects was only $4 \%$.

Thus, the evidence for a distinct diabetic cardiomyopathy characterized by an increased left ventricular mass is sparse in the present study. The myocardial alterations in diabetic subjects having been restricted to an increased left atrial size and an impaired diastolic function, at least in elderly diabetic males.

\section{References}

1. Factor SM, M inase T, Sonnenblick E H (1980) Clinical and morphological features of human diabetic cardiomyopathy. A $m$ H eart J 99: 446-458

2. D anielsen R (1990) Cardiomyopathy in type I diabetic subjects: a review with emphasis of noninvasive studies. A $\mathrm{m} J$ N oninvas Cardiol 4: 246-253

3. Shapiro LM (1982) E chocardiographic features of impaired ventricular function in diabetes mellitus. $\mathrm{Br} \mathrm{H}$ eart J 47: 439-444

4. Galderisi M, A nderson KM, Wilson PWF, Levy D (1991) $E$ chocardio-graphic evidence for the existence of a distinct diabetic cardio-myopathy (the Framingham Heart Study). A m J Cardiol 68: 85-89 
5. H edstrand H , A berg H (1976) D etection and characterization of middle-aged men with hypertension. A cta Med Scand 199: 273-280

6. National Diabetes Data Group (1979) Classification and diagnosis of diabetes mellitus and other categories of glucose tolerance. D iabetes 28: 1039-1057

7. Sahn D J, D eM aria A , K isslo J, Weyman A (1978) The committee on $\mathrm{M}$-mode standardization of the A merican Society of Echocardiography: recommendations regarding quantification in $\mathrm{M}$-mode echocardiography: results of a survey of echocardiographic measurements. Circulation 58: 1072-1081

8. Ferraro S, Perrone-Filardi P, M addalena G, D esiderio A, Gravina E, Turco S, Chiariello M (1993) Comparison of left ventricular function in insulin- and non-insulin-dependent diabetes mellitus. A m J Cardiol 71: 409-414

9. M ildenberger R R, Bar-Shlomo B, D ruck M N (1984) Clinically unrecognized ventricular dysfunction in young diabetic patients. I A $\mathrm{m}$ Coll Cardiol 4: 34-238

10. Danielsen R, Nordrehaug JE, Lien E, Vik Mo H (1987) Subclinical left ventricular abnormalities in young subjects with long-term diabetes mellitus detected by digitized $M$ mode echocardiography. A m J Cardiol 60: 143-146

11. D anielsen R (1988) Factors contributing to left ventricular diastolic dysfunction in long-term type I diabetic subjects. A cta M ed Scand 224: 249-256

12. van Hoeven KH, Factor SM (1990) A comparison of the pathological spectrum of hypertensive, diabetic, and hypertensive-diabetic heart disease. Circulation 82: 848-855

13. H amby R I, Z oneraich S, Sherman L (1974) D iabetic cardiomyopathy. J A m M ed A ssoc 229: 1749-1754

14. Weidmann P, B eretta-Piccoli C, Trost B N (1985) Pressor effects and responsiveness accompanying diabetes mellitus. H ypertension 29: 33-42

15. A nderson EA, H offman R P, Balon TW, Sinkey CA , M ark A L (1991) H yperinsulinemia produces both sympathetic neural activation and vasodilation in normal humans. J Clin Invest 87: 2246-2252

15. B erne C, Fagius J, Pollare T, H jelmdahl P (1992) The sympathetic response to euglycaemic hyperinsulinaemia. E vidence from microelectrode recordings in healthy subjects. D iabetologia 35: 873-879 